\title{
ON THE FLOW OF AVALANGHING SNOW
}

\author{
By M. Heimgartner \\ (Eidgenössisches Institut für Schnee- und Lawinenforschung, 726o Weissfluhjoch/Davos, \\ Switzerland)
}

\begin{abstract}
Variation of flow depth of a flowing avalanche caused by a change in the slope angle is examined using Bernoulli's energy equation, used in hydraulics to determine a non-uniform steady flow. This equation is modified for a material with internal friction and a strongly curved track. The calculated flow depths are compared with those obtained by tests with a snow slide. In the flow model dry and turbulent friction are taken into account. Friction coefficients are estimated comparing calculated and measured flow depths. It appears that in wet snow they differ from those of dry snow. Finally, this model is used to calculate the runout distance of a natural avalanche.

RÉsumé. Sur le mouvemsnt d'une avalanche coulante. La variation en épaisseur d'une avalanche coulante causée par un changement de pente est examinée au moyen de l'équation de Bernoulli qui est connue en hydraulique pour déterminer un écoulement stationnaire non uniforme. Cette équation est adaptée à des matériaux possédant un frottement interne et à une trajectoire fortement courbée. Les épaisseurs ainsi calculées sont comparées à celles qui ont été obtenues par des essais sur une glissoire de neige. Dans le modèle d'écoulement un frottement indépendant de la vitesse et un frottement turbulent sont pris en compte. Les coefficients de frottement sont estimés par comparaison des épaisseurs calculées et mesurées. Il apparaît qu'ils diffèrent dans une neige mouillée de ceux d'une neige sèche. Pour finir ce modèle est utilisé pour calculer la distance d'arrêt d'une avalanche naturelle.

Zusammenfassung. Zur Bewegung von Fliesslawinen. Mit der in der Hydraulik üblichen Energiegleichung von Bernoulli für stationär ungleichförmige Abflüsse, welche für ein Material mit innerer Reibung und stark gekrümmte Bahnkurven umgeformt wurde, wird die Fliesshöhenänderung einer Fliesslawine nach einem Gefällsbruch untersucht und mit Messungen auf einer Schneegleitbahn verglichen. Das Abflussmodell berücksichtigt trockene und turbulente Reibung, deren Koeffizienten aus Vergleich der gemessenen mit der gerechneten Fliesshöhe abgeschätzt werden. Es zeigt sich, dass diese Koeffizienten für trockenen und nassen Schnee verschieden sind. Abschliessend wird mit diesem Modell die Auslaufstrecke einer natürlichen Lawine machgerechnet.
\end{abstract}

\section{i. Generalities and assumptions}

In this paper the motion of flowing avalanches is calculated using some methods of technical hydraulics. Avalanching snow behaves differently from water, hence, the equations describing the flow model have to be adapted to the properties of snow. In doing so one has to consider the restrictions made by Salm ( 1968$)$ :

(I) The material is ideal elasto-plastic, similar to a dry sand.

(2) The flow is bi-dimensional and steady, but non-uniform. This non-uniformity is caused by a change in the slope angle.

Furthermore, we assume the friction forces $T$ along the avalanche track to depend upon velocity $v$ like $T=a_{0} v^{0}+a_{2} v^{2}$, where the $a_{i}$ are constants. The viscosity term $a_{1} v^{1}$, is neglected (Salm, 1966). These limitations allow us to describe a flowing avalanche by the Bernoulli equation of non-viscous discharge.

\section{BASIC EQUATIONS}

\subsection{Velocity distribution in a curved channel}

In a curved channel the velocity is not constant over the flow depth $t$, but changes with increasing $z$ (Fig. I), as shown by Franke (197I):

$$
v=v_{0} \frac{R_{0}}{R_{0} \pm z} \text {. }
$$



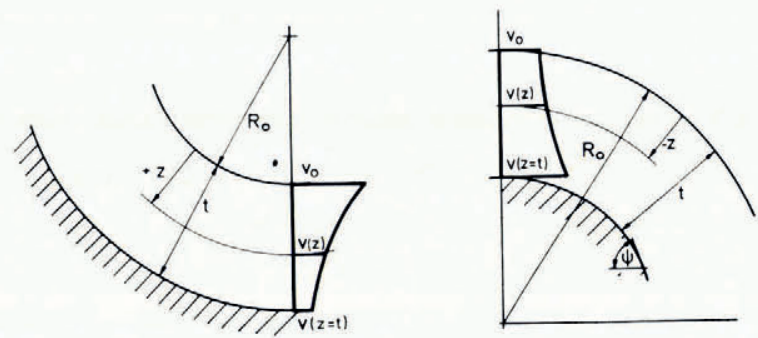

Fig. I. Velocity distribution in curved channels.

$R_{0}$ is the constant radius of curvature at the flow surface and $v_{0}$ the surface velocity. The positive and negative signs are set for decreasing and increasing slope angles respectively. Equation ( $\mathrm{I}$ ) is only valid with a positive denominator. $v_{0}$ may be obtained from the continuity equation

$$
\frac{Q}{B}=\int_{0}^{t} v \mathrm{~d} z=\int_{0}^{t} v_{0} \frac{R_{0}}{R_{0} \pm z} \mathrm{~d} z,
$$

where $Q$ means the constant flow rate and $B$ the flow width. Hence it follows that

and the velocity $v_{t}$ at the depth $z=t$

$$
v_{0}=\frac{Q}{B R_{0} \ln \frac{R_{0} \pm t}{R_{0}}},
$$

when $R=R_{0} \pm t$.

$$
v_{t}=\frac{Q}{B R \ln \frac{R}{R_{0}}},
$$

\subsection{Friction forces on the surface of the avalanche track}

As suggested by Salm (1968), the shearing stress $\tau_{x z}$ between the avalanching snow and the stationary underground is considered to depend linearly upon the normal stress $\sigma_{z}$ acting on the sliding plane, and also upon the square velocity $v^{2}$, the roughness of the avalanche track $k^{-2}$, and the mean gravity of the moved snow $\gamma$, in accordance with the equation of Chézy for turbulent flow. Thus we assume

$$
\tau_{x z}=\mu \sigma_{z}+\gamma v^{2} k^{-2},
$$

where $\mu$ is a dry-friction coefficient.

If the avalanche track is bent with an actual radius of curvature $R, \sigma_{z}$ is set to

$$
\sigma_{z}=t \gamma\left(\cos \psi+\frac{v^{2}}{R g}\right)
$$

where $\psi$ is the slope angle and $g$ is the acceleration due to gravity.

Equations (4) and (5) do not depend upon the material, the only material term being $\gamma$ : thus these equations are valid for plastic and elastic materials.

By inserting Equation (3) into Equation (5) we get

$$
\sigma_{z}=t \gamma\left[\cos \psi+\frac{\mathrm{I}}{g R^{3}}\left(\frac{Q}{B \ln \left(R / R_{0}\right)}\right)^{2}\right] \text {. }
$$

The importance of the second term within the brackets grows with decreasing radius of curvature $R$. 


\subsection{Avalanching snow}

In soil mechanics, soil yielding is often described by the Coulomb criterion for cohesive materials

$$
\tau_{x z} \leqslant \tau_{f}=\sigma_{z} \tan \phi+c,
$$

where $\tau_{x z}$ is the shear stress and $\sigma_{z}$ the normal stress on a plane element. $\tau_{f}$ stands for the shear strength, $\phi$ for the angle of internal friction and $c$ for the cohesion of the considered material. As shown by Terzaghi (Terzaghi and Jelinek, 1954), Equation (7) leads to

$$
c \cos \phi=\left[\frac{1}{4}\left(\sigma_{z}-\sigma_{x}\right)^{2}+\tau_{x z^{2}}\right]^{\frac{1}{2}}-\frac{1}{2}\left(\sigma_{z}+\sigma_{x}\right) \sin \phi,
$$

in the case of plain strain. The directions of the stress symbols $\sigma$ and $\tau$ are explained in Figure 2.

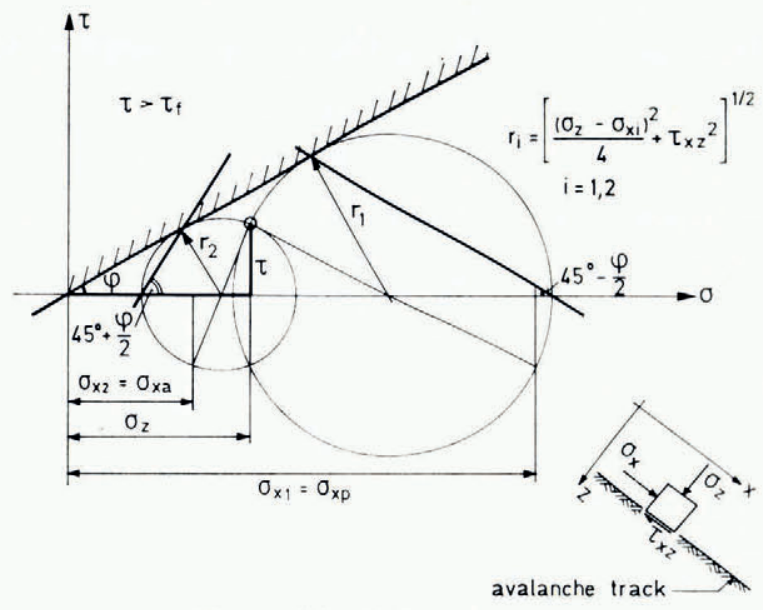

Fig. 2. Mohr-Coulomb hypothesis.

Equation (8) is perfectly compatible with general plasticity theory, as demonstrated by Drucker and Prager (195I).

A dry sand is not cohesive $(c=0)$, and in this case Equation (8) becomes

$$
\frac{\left(\sigma_{z}-\sigma_{x}\right)^{2}+4 \tau_{x z}{ }^{2}}{\left(\sigma_{z}+\sigma_{x}\right)^{2}}=\sin ^{2} \phi .
$$

In an elastic material $\sigma_{x}$ is given by the confined three-dimensional stress state (Ziegler, 1962 ),

$$
\sigma_{x}=\frac{\nu}{\mathrm{I}-\nu} \sigma_{z}
$$

here $\nu$ is Poisson's ratio. Equation (9) is restricted to non-curved tracks.

As long as the stresses $\sigma_{z}, \sigma_{x}, \tau_{x z}$, calculated from Equations (5), (10) and (4), do not fulfil the yield criterion (Equation (9)), the material remains elastic, but as soon as the left side of Equation (9) equals the right-hand side, Equation (ro) is invalidated and $\sigma_{x}$ is obtained from Equation (9):

$$
\sigma_{x_{1,2}}=\sigma_{z}\left[\frac{\mathrm{I}+\sin ^{2} \phi}{\cos ^{2} \phi} \pm\left(\left(\frac{\mathrm{I}+\sin ^{2} \phi}{\cos ^{2} \phi}\right)^{2}-\frac{\cos ^{2} \phi+\alpha^{2}}{\cos ^{2} \phi}\right)^{\frac{1}{2}}\right],
$$

where $\alpha=2 \frac{\tau_{x z}}{\sigma_{z}}$. 
The positive sign gives the maximum value $\sigma_{x_{1}}$, corresponding to the passive stress state of Rankine, and the negative sign the minimum value $\sigma_{x_{2}}$ corresponding to Rankine's active stress state (Fig. 2).

\section{Bernoulli's equation}

Flow depths of non-uniform steady flow are generally calculated stepwise using Bernoulli's equation

$$
H=\frac{v^{2}}{2 g}+\frac{p}{\gamma}+w
$$

$\boldsymbol{H}$ denotes the energy head, $p$ the pressure in flow direction $x$ on the sliding plane, and $w$ the geometrical head.

A friction force $T$ per unit volume, divided by $\gamma$, is obtained from Equation (4):

$$
\frac{T}{\gamma}=\frac{\tau_{x z}}{\gamma t}=\frac{\mu \sigma_{z}}{\gamma t}+\frac{v^{2}}{t k^{2}} .
$$

$T / \gamma$ corresponds to the gradient of the total head, and may be written as

$$
\frac{T}{\gamma}=\frac{\Delta w_{\mathrm{e}}}{\Delta x}=\frac{\Delta w_{\mathrm{e}} \cos \psi}{\Delta u},
$$

from which we obtain

$$
\Delta w_{\mathrm{e}}=\frac{\Delta u}{\cos \psi}\left(\frac{\mu \sigma_{z}}{\gamma t}+\frac{v^{2}}{t k^{2}}\right),
$$

$\Delta w_{\mathrm{e}}$ is the energy loss per length $\Delta u$.

When the pressure $p$ at the slip plane is replaced by $\sigma_{x} \cos \psi$ (Salm, 1968), the equation of non-uniform steady flow of avalanching snow becomes,

$$
H=w_{u}+\frac{v_{u}^{2}}{2 g}+\frac{\sigma_{x u}}{\gamma} \cos \psi_{u}=w_{l}+\frac{v_{l}^{2}}{2 g}+\frac{\sigma_{x l}}{\gamma} \cos \psi_{l}+\Delta w_{\mathrm{e}},
$$

using Equations ( I I) (plastic case) and (Io) (elastic case). Here the index $u$ refers to an upper and the index $l$ to a lower cross-section of the avalanche track (Fig. 3).

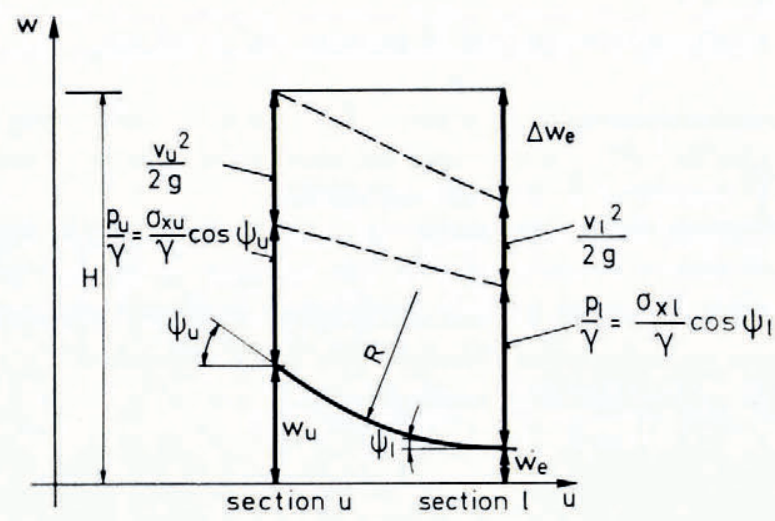

Fig. 3. Bernoulli's equation modified for avalanches.

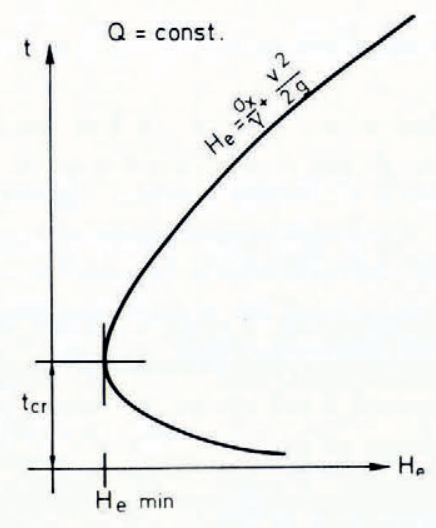

Fig. 4. Specific energy versus flow depth. 
Plotting the specific energy $H_{\mathrm{e}}$ against flow depth $t$ (Fig. 4), where

$$
H_{\mathrm{e}}=\frac{\sigma_{x}}{\gamma} \cos \psi+\frac{Q^{2}}{2 g F^{2}}=\frac{v^{2}}{2 g}+\frac{\sigma_{x}}{\gamma} \cos \psi,
$$

and $F$ is a cross-section of the avalanche track, we obtain a minimum $H_{\mathrm{e}}$ for a critical value $t_{\mathrm{cr}}$. If, in a given flow, $t>t_{\mathrm{cr}}$, this flow is called "streaming", if $t<t_{\mathrm{cr}}$, it is "shooting". A streaming flow changes continuously to a shooting one, this happens inversely in a "hydraulic jump". Hydraulic jumps are calculated with the momentum theorem; in the continuous changes Equation (15) may be used as follows.

I. Calculate $H$ at the first (known) point (Equation (i5)).

2. Take next point: use geometry and an assumed value for $t$.

3. Calculate $\sigma_{z}, \sigma_{x}$ (elastic), and $\tau_{x z}$ (Equations (6), (10), and (4)).

4. Is the yielding function (Equation (9)) fulfilled?

If yes then continue.

If no then go to step 6 .

5. Calculate $\sigma_{x}$ (Equation (I I )).

6. Calculate $\Delta w_{\mathrm{e}}$ (Equation (I4)).

7. Calculate $H$ at the second point (Equation (15)).

8. Is Equation (15) fulfilled?

If yes then take the next point.

If no then go to step 2.

\section{Experiments with the test Slide}

The same tests as those described by Salm (i 968 ) were made, but with a modified snow collector which could contain $25 \mathrm{~m}^{3}$ of snow. A steady flow was maintained for more than $0.7 \mathrm{~s}$ with this modification. Every experiment was filmed, this allowed a measurement of the flow depths behind the deflection point.

TAble I. Measured And Calculated flow Depths for $t_{u}=1.0 \mathrm{~m}$

\begin{tabular}{|c|c|c|c|c|c|c|c|c|}
\hline Test & $\begin{array}{c}\text { Mean snow } \\
\text { temperature } \\
{ }^{\circ} \mathrm{C}\end{array}$ & $\begin{array}{c}v_{0} \\
\mathrm{~m} / \mathrm{s}\end{array}$ & $\mathrm{N} / \mathrm{m}^{3}$ & $\begin{array}{c}t_{\mathbf{2}} \\
\text { measured } \\
\mathrm{m}\end{array}$ & $\begin{array}{c}t_{2} \\
\text { calculated } \\
\mathrm{m}\end{array}$ & $\begin{array}{c}\text { Fitted } \\
\text { coef } \\
\mu\end{array}$ & $\begin{array}{l}\text { riction } \\
\text { ients } \\
k \mathrm{~m}^{1 /} / \mathrm{s}\end{array}$ & $\mu^{\star}$ \\
\hline $2 / 74$ & -3 & 10.2 & $349^{2}$ & I.09 & I.09 & 0.32 & 29 & 0.25 \\
\hline $5 / 74$ & -4 & IO. I & $34^{I} 4$ & 1.05 & I.09 & $0.3^{2}$ & 29 & 0.25 \\
\hline $6 / 74$ & -4 & 10.3 & 3600 & I.07 & I.09 & 0.33 & $3 \mathrm{I}$ & 0.22 \\
\hline $12 / 74$ & -5 & $9 \cdot 5$ & 2531 & 1.09 & I. 12 & 0.33 & 28 & 0.34 \\
\hline $7 / 74$ & -2 & 10.9 & 3630 & I. I 5 & I. 10 & 0.27 & 33 & 0.14 \\
\hline $14 / 75$ & \pm 0 & I0.6 & $457 \mathrm{I}$ & I. 12 & I. I I & 0.27 & $3^{1}$ & o. I 9 \\
\hline I6/75 & \pm 0 & 10.2 & 4405 & I. 17 & I. 13 & 0.28 & 33 & 0.25 \\
\hline
\end{tabular}

Table I compares some test data from the slide inclined at $45^{\circ}$ with the results of a step-bystep calculation using Equation ( $\mathbf{1}_{5}$ ). Two points o and 2 were calculated as shown in Figure 5 , starting at the end of the acceleration part of the test slide and using measured values of velocity and flow depth. The calculations were made with friction coefficients $\mu$ and $k$ as parameters, other values were $\phi=26^{\circ}$ and $\nu=0.25$. The calculated flow depths at point 2 are those which give the best fit with the measured values. The corresponding friction coefficients are also shown.

We can divide these experiments up into two groups. The first 4 tests in Table I were made at low snow and air temperatures, without snow melting. The slide is dry and the friction is high. The remaining tests were carried out at temperatures near $0^{\circ} \mathrm{C}$. The high temperature means that a thin layer of melted snow covers the test slide; this reduces friction. 


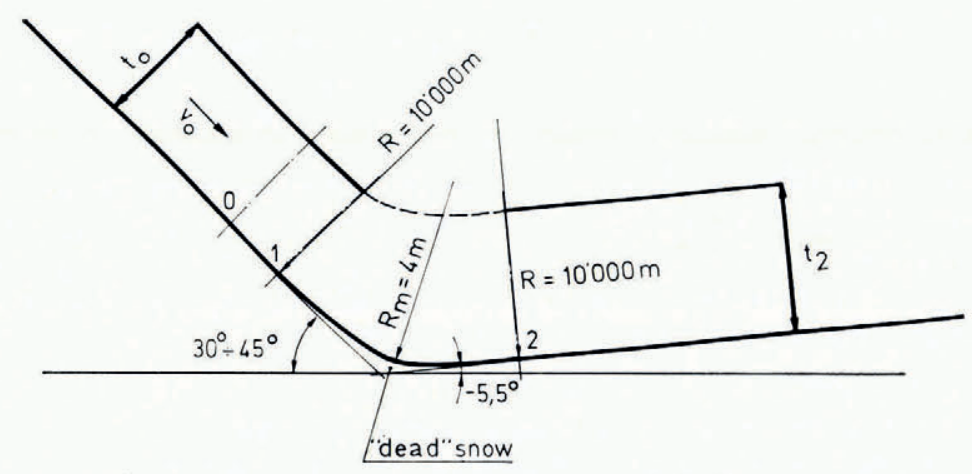

Fig. 5. Flow on test slide at Weissfluhjoch.

The values of $\mu_{*}$ were calculated using the known velocity $v_{0}$, for the acceleration part of the slide (without turbulent friction $k^{-2}$ ).

Plots of $H_{\mathrm{e}}$ (Equation (I6)), show a critical flow depth $t_{\mathrm{cr}}>\mathrm{I} .5 \mathrm{~m}$. All tests began with $t_{0}=\mathrm{I} .0 \mathrm{~m}$, Table I shows that in all cases $t_{2}<\mathrm{I} .20 \mathrm{~m}$. Thus, we conclude that in these tests a continuous flow-depth change in shooting flow occurred without hydraulic jumps; this is confirmed by the cine film.

\section{5. "Skilehrerhalde" avalanche in Parsenn area}

The validity of our conclusions was tested with an artificially released avalanche near our institute; this has been described by Frutiger (1975). Geometrical data for these calculations were obtained by fitting a cubic parabola to the natural avalanche track (Fig. 6).

Friction parameters were set to $\mu=0.18$ and $k^{2}=1700 \mathrm{~m} / \mathrm{s}^{2} . Q$ was calculated with the formula given by Salm (Salm, 1972).

A formula for the runout distance $x_{\mathrm{r}}$ can be derived from Equation (15).

The velocity head $v_{u}^{2} / 2 g$ and the pressure head $\sigma_{x u} \cos \psi_{u} / \gamma$ disappear within the distance $x_{\mathrm{r}}=w_{u} / \sin \psi_{m}$ due to friction $\Delta w_{\mathrm{e}}$. Thus we write

$$
H_{\mathrm{e} u}=H_{\mathrm{e} l}+\Delta w_{\mathrm{e}}, \quad H_{\mathrm{e} l}=\mathrm{o},
$$

and

$$
\frac{v_{u}^{2}}{2 g}+\frac{\sigma_{x u}}{\gamma} \cos \psi_{u}=\Delta w_{\mathrm{e}}-x_{\mathrm{r}} \sin \psi_{m}
$$

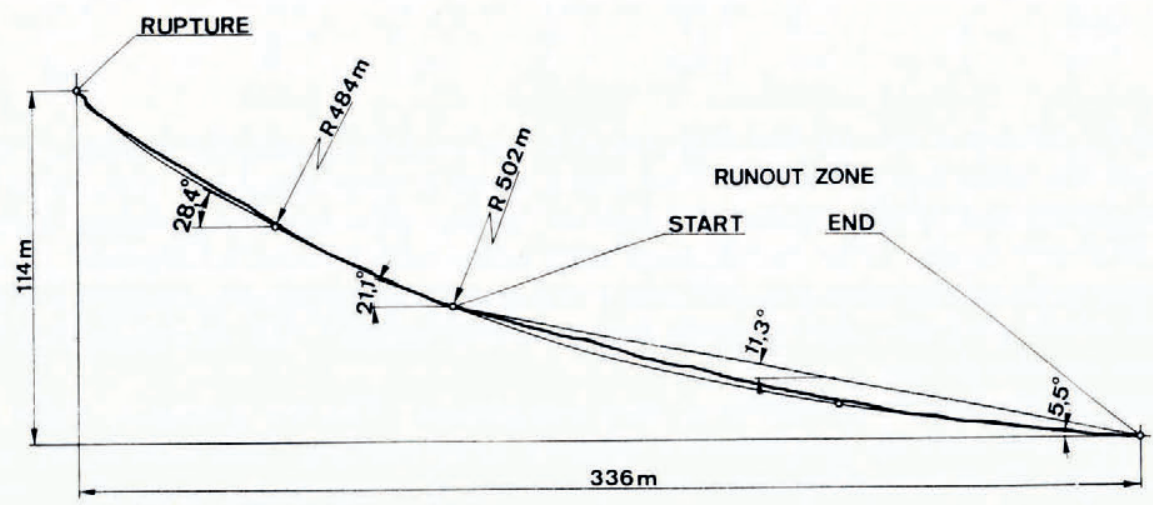

Fig. 6. Track section of "Skilehrerhalde" avalanche, 20 January 1974, Weissfluhjoch/Davos. 
Inserting Equation (14) we get

$$
\frac{\gamma v u^{2}+2 g \sigma_{x} u}{2 g \gamma} \frac{\cos \psi_{u}}{=x_{\mathrm{r}}}\left[\mu\left(\cos \psi_{m}+\frac{v_{m^{2}} R_{\mathrm{o} m^{2}}}{g R_{m}{ }^{3}}\right)+\frac{v_{m^{2}}}{t_{m} k^{2}}-\sin \psi_{m}\right] .
$$

The steady-state equation of Bernoulli is not exactly valid for this case because velocity $v$ is time-dependent. For this reason we have to calculate with mean values.

The quantities labelled with index $m$ denote such values in the runout process. Assuming that the square of velocity decreases linearly along runout $x_{\mathbf{r}}$, as suggested by Voellmy (1955) and Salm (1966), we get

$$
v_{m^{2}}=\frac{v_{u^{2}}}{2}
$$

and

$$
x_{\mathrm{r}}=\frac{\gamma v u^{2}+2 g \sigma_{x u} \cos \psi_{u}}{2 \gamma g\left[\mu\left(\cos \psi_{m}+\frac{v_{u}^{2}}{2 R_{m} g}\right)+\frac{v u^{2}}{2 t_{m} k^{2}}-\sin \psi_{m}\right]} .
$$

The value in Table II was calculated with this formula and agrees well with the measured value of $224 \mathrm{~m}$.

Table II. Observations AND DERIVed data From the artificiallyRELEASED AVALANCHE

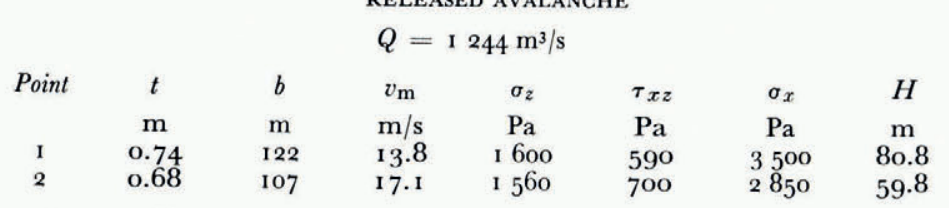

Runout distance $x_{\mathrm{r}}=210 \mathrm{~m}$.

The values in Table II were obtained from Equation (15), the influence of the curved track is negligible.

\section{REFERENCES}

Drucker, D. C., and Prager, W. 1951. Soil mechanics and plastic analysis or limit design. Quarterly of Applied Mechanics, Vol. 10, No. 2, p. 157-65.

Franke, P.-G. 1971. Stationär ungleichförmiger Abfluss in Freispiegelgerinnen. Wiesbaden und Berlin, Bauverlag. (Abriss der Hydraulik, Bd. 7.)

Frutiger, H. 1975. Die Lawine auf der Skilehrerhalde/Davos vom 20. Januar 1974. Berechnung zur Lawinendynamik. Interner Bericht des Eidg. Institutes für Schnee- und Lawinenforschung, Nr. 543.

Salm, B. 1966. Contribution to avalanche dynamics. Union de Géodésie et Géophysique Internationale. Association Internationale d'Hydrologie Scientifique. Commission pour la Neige et la Glace. Division Neige Saisonnière et Avalanches. Symposium international sur les aspects scientifiques des avalanches de neige, 5-10 avril 1965, Davos, Suisse, p.199-214. (Publication No. 69 de l'Association Internationale d'Hydrologie Scientifique.)

Salm, B. 1968. On nonuniform steady flow of avalanching snow. Union de Géodésie et Géophysique Internationale. Association Internationale d'Hydrologie Scientifique. Assemblée générale de Berne, 25 sept. -7 oct. 1967. [Commission de Neiges et Glaces.] Rapports et discussions, p. 19-29. (Publication No. 79 de l'Association Internationale
d'Hydrologie Scientifique.)

Salm, B. 1972. Grundlagen des Lawinenverbaues. Bündnerwald, Beiheft Nr. 9, p. 67-81.

Terzaghi, K., and Jelinek, R. 1954. Theoretische Bodenmechanik. Berlin, etc.: Springer Verlag.

Voellmy, A. 1955. Über die Zerstörungskraft von Lawinen. Schweizerische Bauzeitung, 73. Jahrg., Ht. I2, p. $159-62$; Ht. 15, p. $212-17$; Ht. 17, p. 246-49; Ht. 19, p. $280-85$.

Ziegler, H. r962. Mechanik. I. Basel und Stuttgart, Birkhäuser Verlag.

\section{DISCUSSION}

M. R. DE Quervain: How did you introduce the radius $R=4 \mathrm{~m}$ in the test slide?

M. Heimgartner: It was the minimum value we could introduce with our device. 